\title{
Drop British
}

National Cancer Institute

\section{Source}

National Cancer Institute. Drop British. NCI Thesaurus. Code C69443.

A unit of volume in British Imperial system equal to 1/36 fluid dram or approximately 99 microliters. 